\title{
SEIS CARTAS CRUZADAS ENTRE JORGE GUILLÉN Y GUILLERMO DE TORRE. AUTOBIOGRAFÍA, ESTÉTICA E IDEOLOGÍA A TRAVÉS DE FEDERICO GARCÍA LORCA, PABLO PICASSO Y JUAN RAMÓN JIMÉNEZ ${ }^{1}$
}

\author{
SIX LETTERS EXCHANGED BETWEEN JORGE GUILLÉN \\ AND GUILLERMO DE TORRE. AUTOBIOGRAPHY, \\ AESTHETICS AND IDEOLOGY THROUGH FEDERICO GARCÍA LORCA, \\ PABLO PICASSO AND JUAN RAMÓN JIMÉNEZ
}

ANDRÉS JUÁREZ LóPEZ Universidad Nacional de Educación a Distancia (UNED)

aj171967@gmail.com

Fecha de recepción: 19-04-2019

Fecha de aceptación: 08-09-2019

\section{RESUMEN}

Las seis cartas intercambiadas entre Jorge Guillén y Guillermo de Torre que ofrecemos en el presente artículo son una muestra de la diversidad de modos de relación personal en el panorama literario y artístico anterior y posterior a la guerra civil española. Junto a su valor documental, nos permiten observar el perfil estético, político y autobiográfico de sus corresponsales a través de tres protagonistas de igual talla: Federico García Lorca, Pablo Picasso y Juan Ramón Jiménez, que son en ellas objeto de reflexión y recuerdo.

PALABRAS ClAVE: Jorge Guillén, Guillermo de Torre, cartas, autobiografía, guerra civil

1 Las seis cartas que presentamos son una parte de la edición completa de esta correspondencia, que estamos preparando para su publicación. 


\section{AbStRaCT}

The six letters exchanged between Jorge Guillén and Guillermo de Torre, which we offer in the following article, are an example of the diversity of relationships in the literary and artistic scene, before and after the Spanish Civil War. Besides their documental value, we can also observe the aesthetic, political and autobiographical profile of their authors through three equally valuable characters: Federico García Lorca, Pablo Picasso and Juan Ramón Jiménez, who act as subjects of reflection and memory in the letters.

KEY WORDS: Jorge Guillén, Guillermo de Torre, letters, autobiography, Spanish Civil War

\section{INTRODUCCIÓN}

Las cartas intercambiadas entre Jorge Guillén y Guillermo de Torre, depositadas en sus respectivos archivos personales de la Biblioteca Nacional de España —en torno a medio centenar, escritas a lo largo de casi medio siglo, inéditas en su conjunto hasta la fechason un ejemplo más de las posibilidades que brindan los epistolarios para acceder a nuevas perspectivas de la historia literaria.

Estas cartas ofrecen un indudable valor documental y biográfico, y en ellas hallamos referencias a la vida literaria, editorial y cultural de estos cincuenta años. Además, la escritura epistolar nos proporciona una perspectiva de intercambio de experiencias vitales entre dos escritores de la significación de Jorge Guillén y Guillermo de Torre que ilumina la historia literaria con insuperables concreción e inmediatez.

Como ya indicaba Francisco J. Díaz de Castro en 1998, refiriéndose a los escritores del 27, los epistolarios pueden leerse como una "autobiografía colectiva". Por otra parte, la intensa y extensa labor de edición de epistolarios de la Edad de Plata a lo largo de los últimos veinte años es muestra del interés despertado por este tipo de escritura.

Como un capítulo de esta "autobiografía colectiva", el conjunto de la correspondencia conservada y cruzada entre Guillén y Torre recoge detalles sobre el proceso creativo de las sucesivas ediciones de Cántico y Clamor y de los diferentes artículos y libros de crítica y teoría literaria de Guillermo de Torre — entre los que figuran los dedicados a la obra de Jorge Guillén-, el intercambio de juicios críticos sobre las respectivas obras, noticias acerca de actividades docentes, sobre viajes o novedades familiares de ambos corresponsales. Pero del conjunto, destacan algunos grupos de cartas que iluminan, a modo de estampas y con una precisión casi fotográfica, momentos de enorme significación por cuanto reflejan, a nuestro juicio, modelos de relación artística o literaria, con elementos personales, sin duda, pero igualmente estéticos y también políticos. Entre ellos nos ocupamos de la lectura de Federico García Lorca en el Ateneo de Valladolid, en 1926, de la exposición de Pablo Picasso en Madrid diez años más tarde, y de la confusión por parte de Juan Ramón Jiménez sobre la autoría de la Antología del Alzamiento, de Jorge Villén, ya en los años de posguerra. 


\section{FEDERICO GARCÍA LORCA EN EL ATENEO DE VALLADOLID. ABRIL DE} 1926

Del medio centenar de cartas de la correspondencia, un grupo de ellas gira en torno a la rememoración de la lectura de poemas del poeta granadino en el Ateneo de Valladolid el 8 de abril de 1926, y ello a raíz de hechos relevantes en la vida y en la obra de Jorge Guillén: en primer lugar, tiene que ver con su primer viaje a España tras la guerra civil española, en junio de 1949, en el que rescata las cartas de Lorca; en segundo lugar, con su semblanza "Federico en persona", incluida — no sin la poda de su capítulo final tras pasar por la censura- en la edición de las Obras Completas de Federico García Lorca aparecida en la editorial Aguilar en 1954; y algo más tarde, con la publicación de la correspondencia entre ambos poetas, que Guillén publica en la editorial Emecé de Buenos Aires en 1959 y que incluye la semblanza mencionada, esta vez completa y sin recortes. Entre ambos acontecimientos, el viaje a España y el rescate de la correspondencia, por un lado, y la publicación de los dos libros de Guillén a los que hemos hecho referencia, podemos situar la escritura de estas cartas, que aportan algunos datos sobre el proceso de escritura de "Federico en persona".

El 21 de febrero de 1950, en una de las cartas que ofrecemos, incluida por Carlos García en su edición de la correspondencia de García Lorca y Torre (2009: 431-432), Guillén relata a Guillermo de Torre:

Mi querido Guillermo: me traje de España — adonde fui a ver a mi padre, ya muy anciano y enfermo; sin ese motivo me habría aguantado las ganas de dar una vuelta por allá- me traje la correspondencia de Federico. Y en una postal - mayo del 27-me dice: "Qué bonito resulta Verso y Prosa de este mes. Precioso. El artículo de Guillermo es bonito y me ha gustado aunque yo no merezca tanto. Es tan elogioso que me parece que no soy yo” ¿Qué tiempos aquellos! No hay modo de no sentir muy disminuidos los actuales.

Tres años después, el 18 de abril de 1953, Guillermo de Torre realiza un comentario escueto: "Sí, publique usted pronto las cartas de Federico". Entre ambas fechas podemos situar el proyecto de Guillén de publicar las cartas de Lorca, cuya edición verá la luz en 1959, en Argentina y que será una de las primeras ediciones de parte del epistolario lorquiano.

Antes, encontramos la primera edición de las Obras Completas de Federico García Lorca publicada por Aguilar en 1954. Guillén participó en la misma con su extensa semblanza "Federico en persona", que abre el volumen. La lectura poética de Federico García Lorca en el Ateneo de Valladolid fue uno de los acontecimientos que Guillén trajo a su memoria, con la ayuda de Torre, para abordar dicha semblanza.

La conferencia de Guillermo de Torre en el Ateneo de Valladolid, dos días antes de la lectura de Federico García Lorca, es comentada por Jorge Guillen en una carta del 23 de abril de 1953, fecha en la que, como el propio Guillén menciona, ya tenía escrito el prólogo o al menos una primera versión del mismo, para Aguilar, y en la que solicita a su corresponsal datos precisos sobre su conferencia. 
El texto escrito finalmente por Guillén para la semblanza de Aguilar y Emecé refleja parte de estos sucesos, recogidos en estas cartas, fuente importante para el proceso de creación de "Federico en persona".

Pero lo que nos interesa, además del valor documental de tales datos, es el tono de amistad compartida, de entusiasmo sin matices ante la asistencia de Federico García Lorca. Las palabras de Guillermo de Torre, tanto como las de Guillén, dan cuenta del afecto compartido y también de la nostalgia conjunta de ambos corresponsales ante la común amistad con Lorca.

\section{PRIMERA EXPOSICIÓN DE PABLO PICASSO EN MADRID. MARZO DE 1936}

En la página 5 de El Sol del 7 de marzo de 1936 se anuncia la inauguración, esa misma tarde, de la primera exposición de Pablo Picasso en Madrid, organizada por ADLAN (Amics de l'Art Nou), en el Centro de la Construcción, en el número 32 de la Carrera de San Jerónimo, donde se hallaba la delegación madrileña de ADLAN, —nacida en Barcelonaque se encargó de impulsar Guillermo de Torre y que se constituyó para dar cobertura a la exposición.

Coetáneas al acontecimiento reseñado, las cartas que abordan este asunto tienen el valor de aportar datos y recrear el ambiente de una exposición de relevancia histórica, pues se trataba de la primera muestra de Pablo Picasso que se realizaba en la capital española, tras el paso de la misma por Barcelona y Bilbao, en enero y febrero de ese mismo año, respectivamente.

Guillermo de Torre se encargaría de los preparativos y la organización de la exposición junto a Ángel Ferrant, José Moreno Villa, Gustavo Pittaluga y Luis Blanco Soler y suyo sería el prólogo al catálogo. Guillén también participó, aunque desde Sevilla. Se encargó de dar lectura a una serie de poemas de Picasso, presentando y acompañando a Paul Eluard en el Ateneo sevillano. Las palabras con las que relata su lectura a Torre, en una carta fechada el 12 de febrero de 1936, de la que trascribirnos el siguiente fragmento, nos ofrecen un esclarecedor testimonio del enfoque estético e ideológico que Jorge Guillén realiza de tal lectura, y de paso nos brinda una cala del perfil personal e intelectual del poeta de Cántico:

Ayer tarde charlé largo rato con Paul Eluard, gratísimo, en efecto, y superior. Ha aparecido hoy ya en los periódicos locales el anuncio de la conferencia de Picasso en el Ateneo. Yo, buenamente, haré la presentación. $Y$, — ¿no es esto liberalismo? - leeré dos poemas de Picasso. Sí, ahora que todo es brutalidad intransigente y simplificación cerril, ahora hay que ser más liberal —no ecléctico ¿eh? - que nunca. No conozco nada más antípodas de mi tentativa poética que esos poemas, mejor dicho, que esa "poemada". Pues los leeré, la derramaré.

Es esclarecedora la posición de Guillén en un contexto de extrema crispación política, pocos meses antes del estallido de la guerra civil, y de extrema polarización de las posiciones estéticas en torno al papel de las artes en el ámbito social y político, en torno al debate entre poesía y arte "puros" o "dirigidos" al servicio de la revolución. Y es significativo que 
Jorge Guillén sitúe por encima de diferencias estéticas la comunidad de espíritu en una concepción "liberal" de la cultura y el arte, de la vida y la política, más allá de la "brutalidad intransigente y simplificación cerril".

Esta posición sería en cierto modo compartida por Guillermo de Torre en su artículo "Arte individual frene a literatura dirigida" (analizado por Cano Ballesta, 1972: 161-163), publicado en El Sol pocos días antes, el 26 de enero de 1936, y también comentado por ambos corresponsales en cartas cercanas a la exposición de Picasso.

\section{ALGUNOS DATOS PARA LA HISTORIA DE UNA CONFUSIÓN. LA ANTOLOGÍA DEL ALZAMIENTO, DE JORGE VILLÉN. ABRIL DE 1946}

La correspondencia entre Guillermo de Torre y Jorge Guillén conservada en la Biblioteca Nacional se interrumpe el 3 de junio de 1936 y no se reanuda hasta el 30 de abril de 1940. Guillermo de Torre, tras residir en Buenos Aires entre 1927 y 1932, regresa a Madrid. El estallido de la guerra civil en julio del 36 le lleva a salir de España en septiembre de ese mismo año. Reside hasta comienzos de 1937 en París y desde allí, junto con su esposa Norah Borges, parte de nuevo hacia Buenos Aires, donde residirá hasta el final de sus días. Jorge Guillén sale de España camino del exilio en 1938. Regresará de forma definitiva, fijando su residencia en Málaga, tras la muerte del dictador Franco y la vuelta de la democracia a nuestro país.

Recordamos estos hechos, suficientemente conocidos, para enmarcar en su contexto el episodio protagonizado por Juan Ramón Jiménez a cuenta de la confusión de autoría de la Antología del Alzamiento editada por Jorge Villén en 1939, así como de la traducción del poema de Paul Claudel A los mártires españoles, realizada, esta sí, por Jorge Guillén y publicada por la editorial de Falange Española en Sevilla, en 1937.

Pero retomemos el asunto de la confusión de autoría de la Antología. El 19 de octubre de 1939 Melchor Fernández Almagro publica en $A B C$ un artículo, "Poesía en la guerra", en el que reseña, junto a otras obras, la "Lira bélica y la Antología del Alzamiento, debida la primera a José Sanz y Díaz, distinguido escritor de propia obra crítica, y la segunda a Jorge Guillén, caracterizada por la certera sistematización de la materia".

La confusión de apellidos aparecida en el artículo de Fernández Almagro dará ocasión a la intervención de Juan Ramón Jiménez, pública en la Revista de las Indias, de Bogotá, en abril de 1944, y privada, a través de varias cartas.

La mención en la Revista de las Indias, velada por el uso de iniciales, apareció en el número 64, de abril de 1944, una serie de aforismos reunidos bajo el título "PUNTOS". Entre ellos, figura el de la polémica:

RESPUESTA CONCISA. Es muy curiosa la idea de limpieza de vida y obra que tienen algunos escritores.

Tengo a la vista un periódico de Madrid, 1943, donde el oportunista y falseador general $R$. $G$. de la S. escribe que el único poeta español que no se ha manchado en la guerra ha sido....M.M. 
(La agravante es, por si esto fuera poco, sobre todas sus limpiezas, que M. es el hermano de A.)

Y J.G., el mayor hipócrita, también tengo a la vista los papeles, tradujo la Oda del católico Paul Claudel, A los mártires de la guerra española y formó la Antología del alzamiento militar, según crónica del ABC de Madrid.

¿En qué clase de agua transmutarán estos charlatanes públicos y privados su conciencia y su fraseología?

(Jiménez, 1944: 314-315)

En la correspondencia que nos ocupa, la confusión de Juan Ramón Jiménez y el recuerdo de estos acontecimientos están relatados en varias cartas, de las que publicamos la de Guillermo de Torre de 8 de abril de 1946 y la respuesta de Jorge Guillén, de 11 de agosto del mismo año.

A este conjunto de cartas debemos agregar, aunque tengan una relación indirecta con el asunto de la Antología de Villén, otras intercambiadas entre Guillén y Torre, anteriores a la guerra civil, relativas a la polémica de Los cuatro vientos y la sonada ruptura de amistad proclamada por Juan Ramón y comunicada a Jorge Guillén por vía telegráfica en junio de 1933. La polémica de Los cuatro vientos sería el origen de una confrontación que duraría de por vida y que provocaría una nueva disputa pública en la revista Índice de las artes y las letras, en febrero de 1954, con profusión de documentos, cartas y contestaciones cruzadas. Un asunto que se prolongaría hasta el fallecimiento de Juan Ramón Jiménez y que sitúa las cartas de las que ahora hablaremos, de 1946, en el centro temporal de la confrontación, entre 1933, fecha de la inicial ruptura, y 1954, fecha de su último episodio en Índice de las artes y las letras.

Ya que el mismo Jorge Guillén en su carta de 11 de agosto de 1946 habla, sin más, de "las circunstancias" en las que tradujo el poema de Claudel, volvamos la mirada a los años de la guerra civil en los que se desarrollan estos acontecimientos. Escuchemos el relato de Jorge Guillén, recogido en Julio Rodríguez Puértolas (2008: 213-214):

Me sorprendió la guerra en Valladolid; estuve preso en Pamplona del 4 al 9 de septiembre de aquel año 1936; de nuevo en Sevilla, donde era profesor, se me formó expediente y quedé "inhabilitado para cargos directivos y de confianza"; antes de salir de la Península me vi obligado a poner en español un poema de Claudel. Son páginas sin derecho a figurar en una posible colección de mis textos, porque no es mío y no reconozco como mío más que lo firmado libremente por mí [...] La sangre había llegado, en efecto, al río, durante aquella guerra, y a un nivel de circunstancias que produjeron aquel acto de pluma sometida...

Estos acontecimientos han sido abordados, con aportación de documentación, por Guillermo Carnero en su edición de Jorge Guillén, Cienfuegos y otros inéditos (1925-1939) publicada en 2005. En la misma figuran los diferentes oficios y expedientes de que fue objeto el poeta, fechados en el verano de 1937 (Guillén, 2005: 347-377) y que dan cuenta de la situación de un escritor que se encontraba en la España nacional, que tenía claras y directas implicaciones personales, familiares, de amistad y de pensamiento con la España de la 
República y que había sido encarcelado en Pamplona el verano anterior, junto a su esposa, Gemaine Cahen.

Volvamos ya a las cartas de Torre y Guillén. Escribe Guillermo de Torre en su carta de 8 de abril de 1946:

[...] Pues bien, espontáneamente, recuerdo que hará ya cerca de dos años, al leer aquella notícula que publicó sobre usted en la "Revista de las Indias", achacándole una "Antología del alzamiento" o algo así, original de un tal Jorge Villén, se me ocurrió decirle —espontáneamente, insisto, por espíritu de probidad, enemigo de confusiones-que ese libro no era de usted pues precisamente en una BiBliografía especial recibida en España acababa yo de verlo registrado bajo el nombre de Villén; que Vd. había hecho la traducción de la oda ominosa de Claudel, quizá forzado por las circunstancias, pero no lo otro. Me replicó diciendo que yo me equivocaba, insistiendo en que la Antología era de usted pues así lo había leído en ABC.

El hecho de que Juan Ramón Jiménez buscaba una aclaración pública por parte de Guillén a su nota de la Revista de las Indias queda claro en el párrafo de la carta del mismo Juan Ramón Jiménez a Guillermo de Torre sobre el asunto y que éste reproduce en la que envía a Jorge Guillén.

Por otra parte, en tres cartas cruzadas entre Juan Ramón Jiménez y Guillermo de Torre (Jiménez y Torre, 2006: 116-128) el primero considera que se trata tanto de una confusión, en el caso de la Antología del alzamiento, que a su juicio requería aclaración pública por parte de Guillén, como de un hecho condenable y denunciable, el de la traducción de Claudel, que debía airearse públicamente para evitar repeticiones. Lo llamativo es que en una de sus cartas Juan Ramón Jiménez vuelve a mencionar el lejano incidente de Los cuatro vientos, y que lo hace en situación de estricta contigüidad textual con la mención a la Oda de Claudel y a la Antología del Alzamiento.

De la contestación de Guillén destacamos la nota de absoluta enemistad, de desengaño personal hacia el maestro, por una parte, y la referencia mencionada a las "circunstancias" de aquellos acontecimientos.

Pues bien, J.R.J. (;oh, sí, los “cansados de su nombre” somos nosotros!) me fuerza a considerarle como mi enemigo número uno. [...] Salí de España en Junio del 38, y no ha habido un solo amigo para quien mi situación no haya estado clara. [...] Claro: hasta ha intentado cobrarse en términos de guerra civil sus venganzas literarias.

Entre las interpretaciones del enfrentamiento realizadas por Jorge Guillén, consideramos que tiene relevancia la escueta pero nítida frase "cobrarse en términos de guerra civil sus venganzas literarias". No entramos, evidentemente, a valorar ambas posiciones, pero sí debemos mostrar el contraste de esta polémica con la actitud y la perspectiva de Guillén en la lectura de los poemas de Picasso que anteriormente hemos comentado. Asistimos a dos situaciones, contemplamos dos estampas separadas por una guerra civil, en las que contrastan la conciliación y la confrontación como fuerzas definidoras e impulsoras de lo estético y lo ideológico. Una evidente distancia estética, la de Picasso y Guillén, resultaba allanada por la voluntad de superar "la brutalidad intransigente y la simplificación cerril". Y una 
afinidad también estética —reconocida por Guillén siempre, al margen del distanciamiento personal - quedaba truncada por la confrontación personal y por las experiencias indelebles de la guerra.

\section{CONCLUSIÓN}

Después de este rápido repaso por algunos de los temas y acontecimientos tratados en estas cartas, podemos concluir que la correspondencia cruzada entre Jorge Guillén y Guillermo de Torre constituye un documento de indudable interés para un más amplio conocimiento de un período que alcanza medio siglo de vida literaria. También, no podía ser de otra forma, para el de sus dos corresponsales.

De manera especial, la selección de tres episodios de la vida cultural de los años previos y posteriores a la guerra civil española centrados en las figuras de Federico García Lorca, Pablo Picasso y Juan Ramón Jiménez, nos ha permitido acercarnos, desde una perspectiva autobiográfica, a tres modos de relación personal y artística que podríamos considerar como categorías relacionales en el contexto de la Edad de Plata y de los años en que se desarrollan tales acontecimientos: la relación de amistad, tan característica del momento, en el caso de Lorca; la consideración secundaria de las diferencias estéticas, frente a una ideología liberal situada por encima de aquéllas, en el caso de Picasso; y finalmente, en el de Juan Ramón Jiménez, una confrontación personal, potenciada por las circunstancias de la guerra, que pesó más que las indudables afinidades estéticas.

\section{BIBLIOGRAFÍA CITADA}

Cano Ballesta, Juan. (1972). La poesía española entre pureza y revolución (1930-1936). Madrid. Gredos.

Díaz de Castro, Francisco J. (1998). "La autobiografía del 27: los epistolarios". Monteagudo.

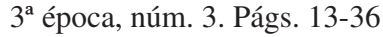

Fernández Almagro, Melchor. (i939) "Poesía en la guerra". ABC, 19 de octubre. Pág. 6

García lorca, Federico y Torre, Guillermo de. (2009). Correspondencia y amistad. Edición de Carlos García. Madrid-Frankfurt am Main. Iberoamericana-Vervuert.

Guillén, JoRge. (1953). “Jorge Guillén replica a Juan Ramón”. Índice de las artes y las letras. Número 72, Págs. 1-10.

Guillén, Jorge. (1954). "Federico en persona”. En Federico García Lorca. Obras Completas. Madrid. Aguilar.

Guillén, Jorge. (1959). Federico en persona. Semblanza y epistolario. Buenos Aires. Emecé.

Guillén, Jorge. (2005) Cienfuegos y otros inéditos (1925-1939). Edición, estudio preliminar y notas de Guillermo Carnero. Valladolid. Fundación Jorge Guillén.

Jiménez, Juan Ramón. (1944). "Puntos". Revista de las Indias. Número 64. Abril. Págs. 308315.

Jiménez, Juan Ramón y ToRre, Guillermo de (2006). Correspondencia 1920-1956. Edición de Carlos García. Madrid-Frankfurt am Main. Iberoamericana-Vervuert.

- Los cuatro vientos (2000). Edición facsímil a cargo de Francisco J. Díaz de Castro. Sevilla. Renacimiento. 
Rodríguez Puértolas, Julio. (2008). Historia de la literatura fascista española. Madrid. Akal.

Torre, Guillermo de (1936). "Arte individual frente a literatura dirigida”. El Sol. 26 de enero de 1936. Pág. 2.

Villén, Jorge. (1939). Antología poética del alzamiento 1936-1939. Cádiz. Editorial Cerón y Librería Cervantes.

\section{SEIS CARTAS CRUZADAS ENTRE JORGE GUILLÉN Y GUILLERMO DE TORRE $^{2}$}

De las cartas de Jorge Guillén @Herederos de Jorge Guillén.

De las cartas de Guillermo de Torre $@$ C Herederos de Guillermo de Torre

\section{[1] Carta de Guillermo de Torre a Jorge Guillén.}

[Carta mecanografiada. Un folio. Tinta negra.]

[Membrete:] ADLAN ${ }^{3}$ / AMIGOS DE LAS ARTES NUEVAS / BARCELONA MADRID TENERIFE / CENTRO DE LA CONSTRUCCIÓN, CARRERA DE SAN JERÓNIMO, 32, TEL. 2 I 499

27 de enero de 1936

Querido Jorge:

Rápidamente unas líneas para contestar a las cosas urgentes que le interesan. De las demás hablaremos cuando usted venga por aquí. Tiene ahora dos buenas ocasiones para ello: ante todo, la aparición de su libro magnífico ${ }^{4}-\mathrm{y}$ que nos reunamos unos cuantos en torno a usted para festejarlo- y después la celebración de la exposición Picasso que inauguramos el

2 Las cartas escritas por Jorge Guillén proceden del archivo personal de Guillermo de Torre de la Biblioteca Nacional de España (signatura Mss. 22824/2). Las escritas por Guillermo de Torre proceden del archivo personal de Jorge Guillén de la Biblioteca Nacional de España (signatura JG/96/3). Agradecemos a Margarita Ramírez y a Miguel de Torre las respectivas autorizaciones para su publicación. Para la transcripción, seguimos las normas del Proyecto Epístola, manteniendo y explicando las enmiendas y correcciones de los propios autores cuando resultan significativas en el contexto de la carta.

3 En 1935, la agrupación catalana ADLAN (Amics de l'Art Nou) — fundada en 1932 con el objetivo de promover el arte de vanguardia - proyectó una exposición - la primera en España - de Picasso en Barcelona. La muestra se pudo ver en la Sala Esteva del 13 al 30 de enero de 1936 y, posteriormente, se llevó a Bilbao, en febrero, y a Madrid en marzo. El papel de Guillermo de Torre en esta exposición de 1936 fue destacado. Torre fue el responsable de impulsar la agrupación catalana en Madrid, y suyo es el prólogo del catálogo de la muestra de Picasso que ocupa esta carta a Guillén.

4 La segunda edición de Cántico. publicada por Cruz y Raya. 
22 del próximo ${ }^{5}$. Extraordinariamente atareado en su preparación, junto con Ferrant, Moreno Villa, Pittaluga y Blanco Soler ${ }^{6}$. Para ello y para celebrar otras exposiciones del mismo corte acabamos de constituir ADLAN. Dentro de unos días recibirá usted la proclama y estatutos. Paul Eluard acaba de llegar a Madrid, como heraldo de los cuadros y portador de los poemas

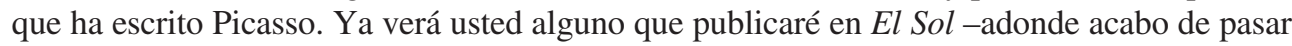
mi colaboración.

Respecto a Sur. Sayons ${ }^{7}$, buen muchacho, pero no creo que pueda cumplir su promesa. Sin ninguna jactancia: soy yo quien asume "todos los poderes" en este asunto. Roto el contrato con Calpe ${ }^{8}$, soy yo el representante para todo y Sánchez Cuesta ${ }^{9}$ el distribuidor de la revista y de las ediciones para España. Él puede suscribirle desde el número que usted quiera. Sin perjuicio de ello, yo le mandaré a usted alguno de los números de la nueva serie - a partir del 10. Acaba de salir el 15 y ahora sale regularmente todos los meses. El estudio de Reyes sobre Mallarmé10 que apareció en el número 9 no ha tenido continuación. A mi parecer acababa allí. O quizá él lo complete, pero será al publicarlo en libro. Puesto que - justificadamente- le interesa tanto, ¿por qué no indaga escribiendo al mismo Alfonso Reyes? Sus señas son: 397 Ruas das Laranjeiras, Rio de Janeiro.

La agencia de recortes más experta en lo literario y de que nos servimos nosotros en el Centro $^{11}$ es La Información Periodística, Padilla 78, Madrid.

El libro de Denner ${ }^{12}$ no me corre prisa, pero tampoco quisiera perderlo. Mándemelo, pues, o tráigalo, cuando le parezca mejor.

Gracias por los saludos de ustedes para Norah —que está ahora en Buenos Aires, de visita familiar- y reciba ["reciba", manuscrito en tinta azul] los míos para Germaine y sus chicos. Con un abrazo muy cordial de su siempre amigo Guillermo de Torre [manuscrito]

5 En El Sol de 7 de marzo de 1936 aparece reseña de la exposición. En el de 14 de marzo, el periódico reseña una conferencia de Guillermo de Torre sobre Picasso dada por radio.

6 Ángel Ferrant, José Moreno Villa, Gustavo Pittaluga y Luis Blanco Soler.

7 Alfonso de Sayons, poeta franco-argentino, también cineasta a mediados de los años 30 del pasado siglo. Autor del libro de poemas Oda y Jornada, editado por Manuel Altolaguirre en Mexico en 1941. De su extraña biografía, que termina en Italia con un secuestro de la Mafia, ofrece noticias Julio Neira en Manuel Altolaguirre. Impresor y editor. Madrid. Consejo Social de la Universidad de Málaga y Residencia de Estudiantes. 2009 (pág. 427)

8 Guillermo de Torre, hasta este momento, había trabajado con Espasa-Calpe. Además de su participación en Sur, como indica en esta carta, desempeñará su labor editorial en Losada, fundada por Gonzalo Losada y en la que continuará el resto de su vida.

9 León Sánchez Cuesta (1892-1978), el "librero de la generación del 27", fiel a la internacionalización del saber y la cultura impulsadas desde el institucionismo "convirtió sus librerías de Madrid y París en centros de difusión de la cultura foránea en España y de difusión del libro español en el extranjero”. (Página web de la Residencia de Estudiantes http://www.residencia.csic.es/bol/num5/cuesta.htm, último acceso, el 16 de abril de 2019)

10 En el número 9 de Sur, de julio de 1934, aparece "Culto a Mallarmé. Primera parte. El museo Mallarmé" (págs. 115-151) que incluye los cuatro primeros capítulos de esa primera parte. En el número 26 de Sur, de noviembre de 1936, aparecerá la continuación y conclusión de esa primera parte, con el quinto y último capítulo, titulado "El gabinete de humo" (págs. 43-52).

11 El Centro de Estudios Históricos, en el que Torre trabajaba por estas fechas, en la sección de Archivos de Literatura Española Contemporánea.

12 Heinrich Denner. Das Stilproblem bei Azorín. Zurich. 1932. Rascher und Cie. 
Recibí la copia del artículo de Salinas que le he enviado y que sale esta semana en el Índice Literario ${ }^{13}$. Ya cuidaré también de mandarle un ejemplar. Ese artículo a mí me parece extraordinario; su interpretación de Cántico distinta e infinitamente más exacta que todas las que se habían hecho. Enhorabuena.

\title{
[2] Carta de Guillermo de Torre a Jorge Guillén.
}

\author{
[Carta manuscrita. Una cuartilla. Orientación horizontal. Tinta roja.] \\ [Membrete:] CENTRO DE ESTUDIOS HISTÓRICOS / ARCHIVOS DE LITERATURA CONTEMPORÁ- \\ NEA / ÍNDICE LITERARIo / MADRID MEDINACELI, 4 / TELÉFONO 24660
}

27 de marzo de 1936

Querido Jorge:

Le he hecho enviar un catálogo de la exposición Picasso. Resultó muy bien. 5.000 visitantes de pago y 1.500 de mis Picasso $^{14}$ vendidos. Preparamos otras exposiciones. El público de Madrid no está tan entontecido como parece y aún sabe reaccionar cuando se le brindan novedades y valores auténticos.

Con esos trabajos, artículos y un viaje último no recuerdo ahora si ya contesté a la carta en que me preguntaba las señas actuales de Chabás ${ }^{15}$ y de Quiroga Plá ${ }^{16}$. El primero, inhallable o invisible, por Madrid desde hace meses. Debe de estar "faranduleando" por provincias. Las señas de Quiroga, en Salamanca, son las mismas de Unamuno: Bordadores, 4.

Recibido el libro de Denner. En un próximo nº de Índice daremos la prensa de su Cántico.

Muy cordial abrazo de Guillermo.

13 “El Cántico de Jorge Guillén”, Índice Literario IV, publicado el 10 de diciembre de 1935.

14 Referencia al catálogo de la exposición, prologado por Guillermo de Torre.

15 Juan Chabás (1900-1954). Miembro de la generación del 27, pensionado por la Junta de Ampliación de Estudios, trabaja en el Centro de Estudios Históricos, al igual que Torre, participa en la conmemoración del centenario de Góngora y colabora en las principales revistas de los años anteriores a la guerra civil (La Gaceta Literaria o Revista de Occidente, entre otras). Poeta y, fundamentalmente, prosista destacado con libros como Puerto de sombra (1928) y Agor sin fin (1930) en los que aporta una de las manifestaciones más significativas de la prosa de vanguardia del momento. Mantuvo una clara defensa de los valores republicanos. Escribió sobre el fascismo a raíz de su estancia en Italia en Italia fascista (Política y literatura) publicado en 1928. Tras la guerra civil española se exilió en Francia y en República Dominicana, Venezuela y Cuba.

16 José María Quiroga Plá (1902-1955), poeta, ensayista y traductor. Vinculado al movimiento ultraísta, participó en las publicaciones relacionadas con el centenario de don Luis de Góngora. Fue secretario de Miguel de Unamuno, con cuya hija, Salomé Unamuno, contrajo matrimonio en 1928. Durante la República desempeñó varios cargos públicos. Tras la guerra civil se exilió en Francia y en Suiza. 


\section{[3] Carta de Guillermo de Torre a Jorge Guillén.}

[Carta mecanografiada. Dos folios. Tinta negra.]

Juncal 1283, O bien:

Editorial Losada

Alsina 1131

Buenos Aires

8 de abril de 1946

\section{Sr. D. Jorge Guillén.}

Querido amigo:

Muy sinceras gracias por el envío de su Cántico $^{17}$, reflorecido y aumentado. Como ya no está uno en edad — es un modo de decir — de ofenderse por nada; como, por otra parte, ningún compromiso subsiguió a la petición que yo le hice de ese libro para la Editorial Losada; como, por último, probablemente ha tardado menos tiempo en componerse, y además han podido respetar mejor, sin sujeción a formatos ni colecciones, el gusto del autor, me parece muy bien que haya salido en Litoral. De veras. Por lo demás, en libros de poesías, y respecto a los que hemos publicado, ha podido casi siempre más el compromiso — de otros, no mío, por supuesto- que la libre elección. Pero en fin, está visto, es tradicional que los buenos libros de poesía escapan a los editores grandes. Puestos a descreer, de acuerdo con el público, en el género, lo sensible es que no se acierte en las excepciones.

Volveré a leer su libro, particularmente las partes nuevas, con gran placer. Y aunque en realidad ahora hago muy pocas notas de libros - esperando tener tiempo así para otros trabajos más largos, que sólo avanzan muy lentamente- si publico algo, refundiendo la de hace años en $E l S_{S o l}^{18}$, no dejaré de mandársela. Por lo demás, mi concepto de la poesía ha sufrido más quiebras y cambios que ningún otro. En principio, como género, apenas me interesa, en relación con lo que me apasionó hace años. A lo lírico puro, tan invasor, preferiría algo épico — algo que si no acabará por verterse enteramente en la novela. En fin, desisto de expresarme con rasgos tan rápidos, por miedo a traicionarme. Todo ello tendré que escribirlo más despacio, ordenando muchos apuntes que tengo desde hace años. ¡Que los verdaderos poetas como usted no se me enfaden, no me interpreten mal ante mis probables "herejías" es lo que entonces pediré!

Desde hace tiempo, querido Jorge, quería y no quería escribirle sobre un fastidioso asunto juanrramoniano - como todos los suyos. Por lo mismo que yo nunca he sido muy amigo de J.R.J. tampoco nunca puedo enemistarme francamente con él. De suerte que le sigo la corriente hasta donde me conviene - y luego le abandono. Me salva probablemente

17 Guillermo de Torre se refiere a la tercera edición de Cántico-Fe de vida-, aparecida en 1945 en México, editada por Manuel Altolaguirre en Litoral. Esta carta hace referencia, igualmente, al ofrecimiento realizado a Jorge Guillén por parte de la editorial Losada para esta tercera edición de Cántico.

18 Es probable que Guillermo de Torre se refiera al artículo aparecido en El Sol, diez años antes, el 23 de febrero de 1936, con motivo de la segunda edición de Cántico. 
el no haber experimentado nunca ningún fetichismo por su persona, el no haberle tomado jamás como oráculo, a diferencia de tantos otros. Resumiendo: como consecuencia de las relaciones trabadas hace años entre la Editorial Losada y Juan Ramón ${ }^{19}$ —relaciones fructuosas para ambos, particularmente por las constantes reediciones de Platero- - y al margen de lo, diríamos, oficial, también alguna carta de tono más particular he tenido ocasión de cruzar con él. Pues bien, espontáneamente, recuerdo que hará ya cerca de dos años, al leer aquella notícula que publicó sobre usted en la Revista de las Indias ${ }^{20}$, achacándole una Antología del alzamiento o algo así, original de un tal Jorge Villén ${ }^{21}$, se me ocurrió decirle espontáneamente, insisto, por espíritu de probidad, enemigo de confusiones- que ese libro no era de usted pues precisamente en una Bibliografía especial recibida en España acababa yo de verlo registrado bajo el nombre de Villén; que usted había hecho la traducción de la oda ominosa de Claudel $^{22}$, quizá forzado por las circunstancias, pero no lo otro. Me replicó diciendo que yo me equivocaba, insistiendo en que la Antología era de usted, pues así lo había leído en $A B C$. Le repliqué a mi vez que debía haber leído mal o tratarse de una errata de periódico y que más confianza me inspiraba una Bibliografía oficial del Instituto Nacional del Libro de Madrid. Creo que quedó la cuestión [ "cuestión”, manuscrito sobre "cosa”, tachado] así por varios meses, sin que yo volviera a preocuparme de ella, pues a mí no me obsesionan ni mucho menos cosas así. Pero J.R.J. volvió a la carga hace meses, en diciembre del año pasado, incitándome a que yo le escribiera a usted pidiéndole una aclaración terminante. Desde entonces he dejado pasar la cosa, sin hacer el menor caso, precisamente para demostrarle que yo no comulgo con sus fanatismos (ni tampoco con el fanatismo de sus enemigos, ni menos con el jesuitismo bergaminiano, ni con ninguna de esas virguerías) y sin escribirle a usted la menor cosa. No quiero ser tercero en discordia [veintidós letras tachadas, ilegible] ni recibir distraídamente ningún palo por asuntos que realmente no me interesan de un modo profundo. Yo con puntualizar aquello, cumplí, y no con usted, con la verdad. Pero en fin, el escribirle ahora, [tachado: "y aunque sólo sea a título anecdótico — desde mi punto de vista —”] le transcribo ahora las líneas concernientes de esa carta del 10 de diciembre pasado y las que hasta hoy [ "hoy" manuscrito, sobre "ahora", tachado] no había querido dar curso [sic]. Dice así el hombre que vive en "Dorchester House", 248) Sixteenth Str, Washington, y con el cual, después de todo, debiera usted aclarar, directamente ["directamente" manuscrito, sobre "después de todo", tachado] el asunto, comunicándome a mí — a título informativo — el "score" 23 y nada más... "Yo le tengo a usted, Guillermo de Torre, por un amigo honrado mío, como yo lo soy de usted, y tanto por usted

19 La obra poética de Juan Ramón Jiménez, tras la guerra civil, se imprimió fundamentalmente en Losada a lo largo de la década de los años 40. Losada se encargó de publicar, junto a otras obras, Platero y yo en 1942, con numerosas ediciones. El contacto y la relación entre Juan Ramón Jiménez y Guillermo de Torre era, por tanto, habitual, hecho que queda reflejado en la correspondencia mantenida entre ambos, editada por Carlos García (Correspondencia 1920-1956. Iberoamericana-Vervuert. Madrid.2006).

20 Se trata de la nota publicada en Revista de las Indias, Bogotá, abril de 1944.

${ }^{21}$ Jorge Villén. Antología poética del alzamiento 1936-1939. Editorial Cerón y Librería Cervantes. Cádiz, 1939.

22 Paul Claudel. A los mártires españoles. Versión española de Jorge Guillén. Secretaría de ediciones de la Falange. Sevilla. 1937.

23 Score: en inglés. marcador, resultado. 
como por Guillén, como por mí, le pido que le escriba usted a él mismo preguntándole si no es cierto que por los años 1939 o 40 (yo estaba en Miami) publicó Melchor Fernández Almagro en el $A B C$ de Madrid una crónica sobre libros recientes donde atribuía a Jorge Guillén, no Villén ${ }^{24}$, el libro consabido, emparejándole con otro de tema análogo reunido por Gerardo Diego ${ }^{25}$. Yo que no tenía ni tengo trato directo con Jorge Guillén envié este ABC a persona amiga de Jorge Guillén y mía, para que él rectificara, ya que yo creía que él debía hacerlo. Que yo sepa, él no ha rectificado nunca públicamente en América ni en España ese supuesto error. Ha rectificado en carta particular ${ }^{26}$, pero ¿por qué no lo ha hecho públicamente después de mi nota de Revista de las Indias? Yo, por lo menos, no he leído su rectificación. Y si cuando Jorge Guillén le conteste, quiere usted comunicarme lo que le diga, que tiene que ser lo que yo digo, puesto que yo he tenido en mi poder dicho $A B C$, se lo agradeceré mucho..."

Ahí quedan, pues, transcritos los párrafos que le conciernen. Si la atribución del librejo es errónea, como yo he creído siempre, hace mucho tiempo, en mi opinión, que debiera usted haber replicado directa y pública [ "y pública” añadido, mecanografiado, en el margen izquierdo] y categóricamente, sin intermediarios, a J.R.J. Pero en fin, no agrego más y me salgo en seguida del asunto, pues repito que odio todos los fetichismos, sectarismos, persecuciones del prójimo, intervenciones en lo ajeno; en dos palabras, el totalitarismo ${ }^{27}$ llevado a las letras...

Acabo de publicar un libro sobre Guillaume Apollinaire, su vida, su obra, las teorías del cubismo $^{28}$. Lamentablemente, como el editor en este caso no es mi casa, sino Poseidón, especializada en libros de arte, con grabados, y me da muy pocos ejemplares, aún insuficientes para cumplir con los compromisos más próximos, dudo que pueda mandarle alguno. Excúseme, pero quizá a esas espléndidas bibliotecas universitarias que tienen ustedes llegue algún ejemplar.

¿Cómo están ustedes? ¿Y el chico suyo que fue a la guerra? ${ }^{29}$ Como no creo en los laureles que de ella se deriven sólo le deseo que haya vuelto intacto.

Con el afecto y la camaradería leal de siempre, reciba un cordial abrazo de

Guillermo de Torre [manuscrito]

24 En $A B C$, el 19 de octubre de 1939, encontramos el artículo de Melchor Fernández Almagro, "Poesía en la guerra", en el que se atribuye erróneamente la Antología poética del alzamiento a Jorge Guillén.

25 El artículo de Melchor Fernández Almagro no habla de Gerardo Diego sino que menciona la antología $L a$ lira bélica, de José Sanz. El comentario, creemos que muy intencionado, de Juan Ramón Jiménez sobre Gerardo Diego no resultaría gratuito en este contexto, pues este último publicó algunos versos de exaltación franquista.

${ }^{26}$ La carta remitida a Juan Ramón Jiménez fue reproducida por Jorge Guillén en Índice de Artes y Letras, en su número de febrero de 1954.

27 Resulta significativa esta asociación de Guillermo de Torre entre el trato personal, el literario y el político.

28 Guillermo de Torre. Guillaume Apollinaire. Su vida, su obra, las teorías del cubismo. Buenos Aires. Editorial Poseidón. 1946.

29 En la Segunda Guerra Mundial, Claudio Guillén se alistó como voluntario en las fuerzas del general De Gaulle, y entre 1943 y 1946 estuvo en África del Norte y en el frente del este de Francia durante el avance de las tropas aliadas. 


\section{[4] Carta de Jorge Guillén a Guillermo de Torre.}

[Carta manuscrita. Tres folios. Orientación vertical. Tinta negra. Dos perforaciones en los márgenes izquierdos. ]

Wellesley, Mass.

6 Norfolk Terrace

11 de agosto de 1946

Mi querido amigo: tengo que empezar por agradecerle varias cosas y por excusarme del retraso con que le contesto. Leí La Aventura y el $\operatorname{Orden}^{30}$ de cabo a rabo. Y con mucho interés, tomé algunas notas y pensé comentarlas. Pero el tiempo va más deprisa que mi poca diligencia epistolar, y ya se me ha ido el santo al cielo. Esos ensayos — como los que publica, y no con bastante frecuencia en Sur - son ante todo reveladores de madurez. Me gusta esa palabra y me gusta la sazón que significa. Madurez, sí, ponderada justeza, sensata justicia. Estoy harto de estridencias, querido Guillermo, nada más fácil que extremar las cosas; nada más difícil que llevarlas a su punto justo — que no es nunca o casi nunca un término medio ni extremo. Acertar exactamente con la verdad: de eso se trata. ¿Qué fácil todo el resto! Ese tono de ponderación y de serenidad tiene su carta. Me habla usted de una pequeña intriga desagradable, y no puede usted hacerlo con más altura y nobleza, con más visible "detachement" 31 . Yo no sé cómo ponerme a tono de su tono y evitar las palabras gruesas que - contrariamente a mis costumbres - me provocan las actuaciones de J.R.J. Usted lo sabe: yo, modestamente, no he logrado inspirar más que amistades, y la categoría de "enemigo" me ha sonado siempre con sonoridad no sólo odiosa sino ridícula — dentro de mi modesta vida privada. Pues bien, J.R.J. (¡oh, sí, los "cansados de su nombre”32 somos nosotros!) me fuerza a considerarle como mi enemigo número uno. La campaña es continua: ataques de todo género, "críticos", satíricos, "eticoestéticos", calumniosos. Claro: hasta ha intentado cobrarse en términos de guerra civil sus venganzas literarias. Y eso sí que es de veras vulgar: igual que nuestra peor gente. Salí de España en junio del 38, y no ha habido un solo amigo para quien mi situación no haya estado clara. Hasta el "amigo" de J.R.J., autor de una lamentable Antología publicada en México ${ }^{33}$, acaba de suprimir en la segunda edición — aparecida ahora- los "datos" equivocados con que adornaba mi semblanza. Hasta Domenchina ha rectificado. J.R.J. no es capaz de rectificar. "Picó" naturalmente en la errata

30 Guillermo de Torre. La aventura y el orden. Buenos Aires. Editorial Losada. 1943. Este conjunto de ensayos es una muestra de la evolución del pensamiento literario de Guillermo de Torre, desde sus inicios, en el movimiento ultraísta. Literaturas europeas de vanguardia, cuya primera edición data de 1925, fue título de referencia por lo temprano de su fecha. La aventura y el orden es un paso más en un proceso de maduración en el ejercicio de la crítica y de la reflexión literarias.

31 En inglés: imparcialidad, objetividad, desprendimiento.

32 Referencia —irónica - de Guillén a la denominación que Juan Ramón Jiménez se aplicaba a sí mismo, consecuencia de la identificación de su persona y la poesía. El uso de sus iniciales respondía a ese mismo "cansancio". Esta denominación y tono ya aparecen en carta de Guillén, remitida a Guillermo de Torre, el 20 de abril de 1935 .

33 Juan José Domenchina. Antología de la Poesía Española Contemporánea (1900-1936). México. Editorial Atlante. 1941. 
"Villén-Guillén". Se lo advirtió usted en carta documentada, invocando un testimonio irrecusable. (Yo le agradezco mucho su intervención). Yo me decidí, por una vez, a responderle y le escribí unas líneas terminantes. Pues nada; imagínese el nivel humano, "eticoestético" desde donde —encontrándose en Washington— escribe a un amigo de Buenos Aires ${ }^{34}$ para que escriba a los Estados Unidos solicitando una polémica pública...Sí, J.R.J. quiere hule ${ }^{35}$, y a todo trance enredar, perjudicar ("con la más solemne perfidia hacer todo el daño posible", como yo le decía en mi carta), en suma, exacerbar el chisme- que es de lo que vive ese caballero. ¡Chisme, chisme, chisme! —es decir, "cisma" — pero en su nivel más degradado: eso es lo que recubre esa "poesía desnuda". Poesía en cuya importancia continúo creyendo, pero de la que no trataré jamás por escrito, porque "imp[osibl]le la has dejado"36, por lo menos para mí. Ni crítica, ni polémica; menos aún una semblanza del J.R.J. que me ha tocado en suerte. La negación no es mi cuerda, y tras el Cántico en verso, yo no quisiera hacer — si tuviese tiempo- más que alguna crítica afirmativa. Dejemos a J.R.J. entre sus chismes. Yo tengo toda mi familia en España, y no ha llegado el momento de aclarar por qué, si no hice la "Antología de Villén, tuve que traducir ("¿sabe usted en qué circunstancias lo hice? - le decía al Chismoso) el poema de Claudel. (;Y ahí es donde quisiera llevarme el Andaluz Particular!) Todo se resume en una sola palabra: vulgaridad [doble subrayado]. Ese el fondo eticoestético de J.R.J. como persona.

Me anuncia usted que va a leer y releer Cántico. También le agradecería que no dejara usted de prestar atención al librito de Joaquín Casalduero que acaba de publicar La Cruz del Sur en Santiago de Chile ${ }^{37}$. Es una interpretación que a mí me parece, en conjunto, muy acertada. La gente no sabe todavía que Casalduero es uno de nuestros primeros críticos. (Podría perfectamente doblar el volumen de su "Galdós" 38 en una segunda edición, porque tiene hecho un estudio mucho más minucioso y desarrollado del gran novelista. (¡Qué grande, verdad?) Si ustedes le animasen, acaso lo hiciera. Conocemos mal nuestra literatura joven -la que es ahora joven. (¡La nuestra lo fue!) A propósito. No deje de enviarme el artículo que sobre ese asunto va usted a publicarle a Ricardo Gullón ${ }^{39}$. (Yo no le conozco, pero a él le debo una de las poquísimas cartas que he recibido de España en estos últimos tiempos; y en ella se refería a ese artículo. ¿Y la joven literatura española en Buenos Ai-

34 Guillén se refiere aquí al propio Guillermo de Torre para subrayar el gran rodeo (Washington-Buenos Aires-Wellesley) de la polémica.

35 "Querer hule": querer sangre. Una de las acepciones del DRAE indica para "hule": "6. Mesa de operaciones en la enfermería de una plaza de toros"; otra, "4. Jaleo o bronca".

${ }_{36}$ Referencia al Tenorio de Zorrilla: «Yo la amaba. Sí. / Mas con lo que habéis osado, / imposible la hais dejado / para vos y para mí». Don Juan Tenorio, Acto IV, Escena VI, vv 467-470).

37 Jorge Guillén, Cántico, de Joaquín Casalduero, uno de los críticos que más prolongadamente abordó el estudio de la poesía guilleniana, apareció en 1946, como indica el poeta en esta carta, en Santiago de Chile, en la editorial La Cruz del Sur.

38 Vida y obra de Galdós (1843-1920) editada por Losada, en Buenos Aires, en 1943.

39 Se trata del artículo "Carta de España. Actualidad literaria en la Península", Sur, núm. 143, Buenos Aires (septiembre 1946), pp. 53-60. 
res? Lorenzo Varela ${ }^{40}$, Serrano Plaja ${ }^{41}$; ¿quiere usted hacerme el favor de enviarme sus direcciones? Los nombres nuevos en España son infinitos; pero hasta ahora no hay manera de orientarse. Por cierto, acabo de ver una Historia y Antología de la Poesía Castellana editada por Aguilar ${ }^{42}$. Es la más extensa y la peor de todas nuestras Antologías, ¡y ya es decir! ¿Ha visto usted ya El contemplado ${ }^{43}$ de Pedro Salinas? Pedro ha regresado de Puerto Rico ${ }^{44}$ muy cargado de obra: ensayos, comedias, poesías, un libro sobre Jorge Manrique ${ }^{45}$ y otro sobre Rubén Darío ${ }^{46}$. Lo único que tiene ya "colocado" — en México— es, naturalmente, el Rubén Darío. (Vaya el informe a usted como editor.) Me pregunta usted por mis hijos. Teresa con su marido ${ }^{47}$ — profesor en Princeton, ahora ultimando un libro (que ha sido su tesis doctoral) sobre el "Quijote" de Avellaneda—y con su hijo — espléndido Antoñito- está ahora con nosotros. Claudio, ahora en Middlebury, vendrá a Wellesley con Pedro esta semana. Acaba de conseguir una beca para estudiar Literatura Comparada en Harvard ${ }^{48}$. Será alumno — qué suerte la suya- de Amado Alonso ${ }^{49}$. Yo estoy trabajando en el cuarto y definitivo Cántico ${ }^{50}$. Escríbame.

\section{[5] Carta de Jorge Guillén a Guillermo de Torre.}

[Carta manuscrita. Un folio. Orientación vertical. Tinta negra.]

[Anotación a lápiz rojo en el margen superior derecho:] R. 27-II-50

40 Lorenzo Varela Vázquez (1916-1978), poeta de origen gallego, criado en Argentina, trasladado en la década de los 30 de vuelta a su tierra natal, reside en Madrid a partir de 1935; allí participa en los ambientes intelectuales liberales y republicanos: colabora en el diario El Sol, en 1936 participa en la Alianza de escritores antifascistas para la defensa de la cultura, ya en la guerra colabora en revistas del bando republicano, como El mono azul y Hora de España. En julio de 1937 participó en el II Congreso Internacional de Escritores para la Defensa de la Cultura, en Valencia.

${ }^{41}$ Arturo Serrano Plaja (1909-1979), participó en Hora de España, en el II Congreso Internacional de Escritores para la Defensa de la Cultura, de Valencia. Tras la guerra se exilió a Argentina, Francia y Estados Unidos. Algunos de sus libros de poesía son El hombre y el trabajo, de 1938 o Versos de guerra y paz de 1944. También cultivó la narrativa y el ensayo.

42 Federico Carlos Sainz de Robles. Historia y Antología de la Poesía Castellana del siglo XII al XX. Madrid, Aguilar. 1946.

43 El Contemplado fue publicado por la editorial Stylo, Colección Nueva Floresta, en el año 1946.

44 Salinas permaneció en Puerto Rico entre 1943 y 1946, impartiendo clases en la Universidad de Río Piedras.

45 Jorge Manrique, o tradición y originalidad, apareció en la Editorial Sudamericana, Buenos Aires, en 1947.

46 La poesía de Rubén Darío (Ensayo sobre el tema y los temas del poeta) salió, pese a lo que comenta Guillén en esta carta, en la editorial Losada, en Buenos Aires, dos años después de escrita esta misiva, en 1948.

47 Teresa Guillén estuvo casada con el hispanista Stephen Gilman (1917-1986). La tesis a la que se refiere Guillén daría lugar, como leemos en esta carta, al libro de Gilman Cervantes y Avellaneda. Estudio de una imitación, publicado por el Colegio de México, con prefacio de Américo Castro, en 1951.

48 Claudio Guillén se doctoró en Harvard en 1953.

49 Amado Alonso (1896-1952), discípulo de Menéndez Pidal en el Centro de Estudios Históricos, dedicó sus estudios al ámbito de la fonética, la historia de la lengua, la gramática, la estilística o la crítica literaria. Enseñó Lengua y Literatura Española a la Universidad Harvard desde 1946 hasta el año de su muerte, 1952.

50 La cuarta y definitiva edición de Cántico vería la luz en 1950, en Buenos Aires, Editorial Sudamericana. 
Wellesley, Mass.

6 Norfolk Terrace

21 de febrero de 1950

Mi querido Guillermo: Me traje de España ${ }^{51}$ —adonde fui para ver a mi padre, ya muy anciano y enfermo; sin ese motivo me habría aguantado las ganas de dar una vuelta por allá - me traje la correspondencia de Federico. Y en una postal - mayo del 27-me dice: "Qué bonito resulta Verso y Prosa ${ }^{52}$ de este mes. Precioso. El artículo de Guillermo es bonito y me ha gustado aunque yo no merezca tanto. Es tan elogioso que me parece que no soy yo.” ¿Qué tiempos aquellos! No hay modo de no sentir muy disminuidos los actuales. En otra carta, Federico — siempre tan generoso- me copia unas estrofas de "La sirena y el carabinero" 53 . Estaba yo muy ilusionado creyendo que esa poesía permanecía aún ["permanecía aún", sobre "estaba", tachado con una línea] inédita. Pero en el libro de Díaz Plaja veo - con algunas variantes - el mismo trozo de ese poema. Y dedicado a usted. Ya no recordaba que había aparecido en La gaceta literaria. ¿Por qué se lo dedicó a usted? ¿Posee usted algunos versos más? ¿Le dijo a usted algo sobre ese poema por escrito o de viva voz? Todo esto interesa ya a la historia literaria; y a veces yo, como usted, siento el placer de "la erudición sobre los contemporáneos".

Esta curiosidad me sirve de pretexto para escribirle y enviarle un saludo muy cordial. ¿Qué es de sus trabajos? No deje de remitirme cuanto imprima en libro; de antemano se lo agradeceré. Recuerdos a su mujer y para usted un abrazo de su invariable

Jorge Guillén

\section{[6] Carta de Guillermo de Torre a Jorge Guillén.}

[Carta manuscrita. Tres folios. Papel vegetal. Orientación vertical. Tinta negra]

[Membrete en el margen derecho:] GUILLERMO DE TORRE

Juncal 1283

Buenos Aires

17 de mayo de 1953

51 El primer viaje de Guillén a España, tras haber salido hacia el exilio en 1938, se produjo en junio de 1949.

52 De Verso y Prosa, proyectada y publicada en Murcia por Jorge Guillén junto a Juan Guerrero Ruiz, salieron 12 números entre enero de 1927 y octubre de 1928. Colaboraron la mayor parte de los poetas y escritores del 27. El artículo de Torre apareció en el número 3, de marzo, con el título "Federico García Lorca (Boceto de un estudio crítico inconcluso)". Entre otros, Lorca colaboró en el número de abril de 1927 con una serie de poemas que aparecieron en portada.

53 "La sirena y el carabinero (Fragmentos)", se publicó, dedicado a Guillermo de Torre, en el número 5 de $L a$ Gaceta Literaria, de marzo de 1927, junto a poemas de Rafael Alberti, Pedro Garfias, José María Hinojosa, Emilio Prados, Rafael Laffon, Rogelio Buendía y Manuel Altolaguirre. 


\section{Mi querido y admirado Jorge Guillén:}

Celebro que sea usted el prologuista de la edición de la obra completa de Federico, en un tomo, que prepara Aguilar ${ }^{54}$. La edición mía, de Losada, sigue circulando con un prólogo algo anacrónico ya ${ }^{55}$, que pensaba corregir y actualizar si nos hubiésemos entendido con la familia (algo difícil, como todos los herederos) para hacer aquí esa edición. Mi conferencia en el Ateneo de Valladolid fue el 6 de abril de 1926. Me presentó (dice un recorte de El Norte de Castilla, del día 7, que tengo a la vista) "el secretario del Ateneo Sr. Santelices", "en la imposibilidad de hacerlo personalmente" alguien que no se menciona. ¿Quién sería éste? ¿Usted, Francisco de Cossío? El día 7 dio una conferencia María Teresa León de Sebastián ${ }^{56}$ (así se llamaba entonces). Y el 8 - se anuncia en el mismo recorte- la lectura de Federico, "presentado por el catedrático de Literatura de la Universidad de Murcia y poeta J.G., nuestro distinguido colaborador". Estos son los datos precisos.

Personalmente, yo recuerdo también con exactitud, que Federico fue a Valladolid impulsado por mí. Los días en que recibí la invitación para Valladolid — que me cogió de paso, camino de París, donde en aquella primavera iba a pasar tres meses - andaba yo muy frecuentemente con Federico. Le dije: “¿por qué no vienes tú también”. “—Si me invitaran..." "- ¿Por qué no? Con más motivos que a mî". Y desde la pensión de la calle Alcalá, donde entonces vivía él, cruzamos entonces a Teléfonos ${ }^{57}$. Y le puse a usted un telegrama, diciéndole más o menos, entre bromas y veras: "Imposible ir sin Federico, Invítenlo al Ateneo", pues, en efecto, me costaba separarme de él y preveía que allí, como en todas partes, encantaría a todos. Hicimos, pues, juntos el viaje y nos hospedamos en el mismo hotel. Recuerdo que en el tren fui leyendo un número reciente de la Revista de Occidente, donde aparecía su "Santa Lucía y San Lázaro"58. Federico comenzó su lectura recitando su romance de la "luna, luna" ${ }^{59}$. Mi conferencia se llamaba, por antífrasis, "Refutaciones a mí mismo" y era una serie de escolios y de "crítica de críticos" a lo dicho sobre mis Literaturas europeas de vanguardia. Pasaje subrayado (parlamentariamente) con murmullos y aprobaciones fue uno de acometidas a Eugenio D’Ors ${ }^{60}$, quien me había tachado poco antes,

54 Federico García Lorca, Obras Completas, cuya primera edición en la Editorial Aguilar se publicó en Madrid, en 1954.

55 La primera recopilación de las obras completas de Federico García Lorca fue editada por Losada, entre 1938 y 1946, al cuidado de Guillermo de Torre, quien da cuenta en la introducción de las dificultades de tal recopilación y de la propia labor de edición, debido a la escasa organización de los originales disponibles.

56 María Teresa León Goyri (1903-1988), escritora de la Generación del 27, con una extensa obra narrativa y dramática que abarca cuentos, novelas, piezas teatrales, ensayos y un imprescindible libro de memorias, Memoria de la melancolía (Losada, Buenos Aires, 1970).

57 El edificio de Telefónica, en la Gran Vía de Madrid.

58 Las fechas de Torre no concuerdan, pues "Santa Lucía y San Lázaro" apareció en el número 53, año V, de la Revista de Occidente, de noviembre de 1927; un año después de las anteriores referencias a la lectura de poemas del Ateneo de Valladolid.

59 Romance inaugural del Romancero Gitano (cuya primera edición salió en 1928), sus primeras redacciones datan de 1924.

60 Eugenio D’Ors (1881-1954), Xenius, fue uno de los principales representantes del novecentismo catalán en los primeros años del siglo XX. Con su Glosari se convirtió en referente de la prosa ensayística de su generación. 
en $A B C$, lo mismo que a Cassou (con motivo de "Eloge de la folie" ${ }^{61}$ ) de "alejandrinismo". Recuerdo además una tarde en casa de usted, una visita al museo donde están las figuras de Berruguete, un paseo junto al río; recuerdo que fueron todo[s] a despedirme a la estación, cuando ya salí para París, y que Federico volvió a Madrid con usted y con Alfredo Condon, ${ }^{62}$ un escritor chileno muy amigo nuestro entonces.

En fin, aquí tiene unas notas de la atmósfera de aquellos días para ayudar a sus propios recuerdos y completar la "semblanza" que ahora ha escrito. ¡Tiempos claros, bonancibles, no porque sean pasados, sino porque efectivamente lo fueron!

Y ahora..., bloqueado en este Buenos Aires, que se ha hecho irrecognoscible, pero de donde me sería tremendo tener que desmontarme. De ahí, pues, mis — relativas—nostalgias de la España presente, mis perplejidades respecto a encarar algo nuevo en Norteamérica, ya que todo el Sur está estropeado. ¡Si algo cambiara en España, si esa leve evolución en lo intelectual (lea un artículo muy expresivo en Cuadernos Hispanoamericanos, $\mathrm{n}^{\mathrm{o}} 38^{63}$ ) se extendiera a lo demás.

No me queda espacio ni tiempo para agradecerle todo lo que me dice de Problemática. Pero de veras se lo agradezco. Un muy cordial abrazo de

Guillermo de Torre

61 Jean Cassou. Eloge de la folie. Paris, Emile-Paul frères, 1925.

62 Secretario de la Embajada de Chile en Madrid desde marzo de 1928.

63 Se refiere Guillermo de Torre al artículo de José Luis López Aranguren "La evolución espiritual de los intelectuales españoles en la emigración", que apareció en el número 38 de Cuadernos Hispanoamericanos, como se indica en la carta, de febrero de 1953, en el que se realizaba un intento de acercamiento a los intelectuales exiliados desde la España de la dictadura franquista. En esta tarea se empeñó en buena medida Guillermo de Torre, en su caso desde el exilio americano, en sus muchos años de trabajo y actividad cultural y editorial en Losada. 